\title{
Methods building and printing 3D models historical architectural objects
}

\author{
Ihor Hevko ${ }^{1 *}$, Olha Potapchuk $^{1}$, Iryna Lutsyk ${ }^{1}$, Viktorya Yavorska $^{2}$, and Viktoriia Tkachuk ${ }^{3}$ \\ ${ }^{1}$ Ternopil Volodymyr Hnatiuk National Pedagogical University, Department of Computer Technologies, Ternopil, 46027, \\ Ukraine \\ ${ }^{2}$ Odessa I.I Mechnikov National University, Department of Economic and Social Geography and Tourism, Odessa, 65000, \\ Ukraine \\ ${ }^{3}$ Kryvyi Rih National University, Engineering Pedagogy and Language Training Department, Kryvyi Rih, 50027, Ukraine
}

\begin{abstract}
The authors present methods building and printing three-dimensional models for graphical reconstruction of historical architectural objects. Procedure sequence of the methods is exemplified through building the model of the Parochial Cathedral of St. Mary of the Perpetual Assistance of the 1950s. After analyzing and assessing the most popular specialized software means, the 3DS Max environment is chosen to build a three-dimensional model. Suggested software tools enable increased accuracy, speed and granularity of fixation of complex systems and expanded databases, providing efficient instruments to deal with bulk data and being relevant to new IT achievements. Sequence and content of operations for analytical and modeling cycles are substantiated. The cathedral model is built on the basis of archive photographs and drafts. The authors describe methods and the algorithm of procedures, principles of architectural and spacious modeling to recreate the architectural object. The three-dimensional model is built by applying a stereogram miniature of the destroyed Cathedral. Reconstruction of spacious configuration of the objects is based on parallax assessment of images. Stages of project implementation are determined. There are described methods of implementing modeling by 3DS Max tools and preparing the model for 3D printing in Cura.
\end{abstract}

\section{Problem statement}

It is impossible to replace three-dimensional models in all spheres of human activity including industry, medicine, architecture, construction, design, education, cinema, etc. 3D model design enables assessing technical and physical properties of a modeled object before creating a real sample. The methods of studying a model allow analyzing its size, material and package contents.

The concept of an object or a project is mainly exemplified by videos or pictures based on 3-D graphics. This sets constraints on viewing, as static pictures cannot enable plot change or detailed examination.

Modern potential of 3D graphics and computer hardware capacity enable processing complex scenes online without reducing rendering speed and quality. This has evoked professionals' interest to 3D visualization in various activity spheres.

In architecture and bridge engineering, wider application is given to virtual buildings with inside walks and virtual cities. Photorealistic reconstruction of objects makes it possible to work with object models in museum, reconstruction and commercial projects and while studying [1].

Maintaining and promulgation of cultural heritage are essential for modern society. Development of computers and 3D graphic tools enables preserving cultural achievements not only as pictures or photographs but also as models in their original form or as electronic replicas of real-life objects [2].

A great number of architectural monuments have disappeared without any sizes, drafts or photographs left. For such historical objects, graphic reconstruction as a scientific study is the only means of identifying the lost or destroyed architectural object of a certain time period. Graphical reconstruction of architectural historical heritage reflects the whole bulk of knowledge concerning it available to date [3].

In recent years, there have been numerous museums including the virtual ones with their exhibits being computerized objects. Museums of this kind enable obtaining detailed information on historical achievements, getting to know their origin and facilitating cultural development of society. It also facilitates tourism, thus enhancing regions' economic growth [4].

\section{Research aim}

Nowadays, innovative technologies of 3D graphics, modeling and design enable restoring lost historical

\footnotetext{
${ }^{*}$ Corresponding author: gevko.i@gmail.com
} 
objects. Analysis of the degree of investigation reveals only certain aspects of 3D modeling covered in modern scientific literature. Technologies for selecting software for three-dimensional modeling and methods of working with them are described in the works of D. Banach, T. Boardman, J. Jones, M. Jambruno, K. Osadcha, H. Chemerys [5]. The issues of three-dimensional modeling in architectural design are revealed in the studies of L. Borodkin, M. Rumyantsev, A. Smolin, R. Baryshev, V. Rozhko, I. Popov and others [1-3].

General problems concerning history are highlighted in works by such foreign theoreticians of design as O. Henisaretskyi, V. Hlazychev, N. Mosorova, N. Valkova and O. Lavrentieva. 3D modeling as a design and architecture tool is indirectly touched upon in publications by O. Bodnar, O. Boichuk, and V. Danylenko [6].

Thus, analysis of the researches enables concluding that there are no scientific works reflecting specific features of 3D modeling application in architecture aimed at maintaining the cultural heritage of society that makes the above-mentioned issues under-investigated.

The paper is aimed at disclosing peculiarities of creating and printing 3D models of historical architectural objects in the 3DS-Max environment, this being conditioned by contradictions between the problem topicality and necessity to use modern technologies of 3D modeling.

The research object involves building and printing a 3D model of the Parochial Cathedral of St. Mary of the Perpetual Assistance of the 1950s.

\section{Presentation of main materials}

\subsection{Sequence and content of operations of the analytical and modeling cycles}

$3 \mathrm{D}$ modeling is a separate type of computer graphics, which incorporates necessary tools and techniques applied to building a model of an object in the threedimensional space. 3D modeling techniques of a graphic object include the following main cycles: the analytical cycle (collection of input materials; calculation of object sizes and parameters) and the modeling one (building a draft of an object form; accumulation, carving, stamping, etc.).

Nowadays, 3D modeling is used in almost all fields of human activity including advertising, marketing, industry, computer games, cinema, architecture, design and animation. 3D models of buildings and facilities are an integral part of modern design providing the basis for making object prototypes with maximum granularity.

Stages of building 3D models of monuments and landscapes are specific in their character depending on set tasks and software chosen. However, the most essential components of the methods are general for different modeling objects. While setting a task for modeling, it is necessary to determine the rate of granularity and realism of the end product [7]. Realism of a model depends on selected materials for overlaying textures onto an object. Virtual 3D modeling for architectural buildings is based on solving the task of the efficient layout widespread in the theory of pattern recognition.

Nowadays, there are many software means of various parameters and applications in computer graphics. Choice of software primarily depends on the task set. After selecting functions and means required for solving the task, it is necessary to choose efficient software to build 3D models.

Architects and designers make good use of 3D graphics technologies because they are efficient and easy to use for project implementation. To select the required software environment, a survey was conducted among experts in this field and students who study the basics of $3 \mathrm{D}$ modeling. Based on the survey, the following software products are identified as the most popular: Blender, 3D Max, SweetHome 3D, SketchUpMake, Pro 100, FloorPlan 3D, ARCON 3D Architect, ARCHICAD, Maya, Artlantis, LUMION, Cinema 4d. It should be noted that the most appropriate is the use of environments SweetHome 3D, 3DSMax, FloorPlan 3D, ARCON 3D Architect, ARCHICAD in the architectural direction [5].

As our task is to build a model of an object, we should analyze the above-mentioned programmes to choose appropriate software. Parameters of evaluation quality are chosen according to ISO 9126:2001 Standard in which each characteristic is described by its several attributes [8].

In this case, they include functionality, userfriendliness, efficiency, the programme interface and render quality (the final image after processing) as the most important parameter. As these criteria are not equivalent, importance factors are determined for each of them relevant to the set task (Table 1).

Table 1. Assessment parameters.

\begin{tabular}{|l|c|}
\hline Parameter & $\begin{array}{c}\text { Importance } \\
\text { factor }\end{array}$ \\
\hline Functionality & 3 \\
\hline User-friendliness & 2 \\
\hline Efficiency & 2.5 \\
\hline Programme interface & 1.5 \\
\hline Render quality & 4 \\
\hline
\end{tabular}

Evaluation is performed in the system from 1 to 10 points for each parameter on the basis of working with similar programmes. Total rating evaluation equals a total of points for each parameter multiplied by a corresponding factor. Results of comparison analysis are in Fig. 1.

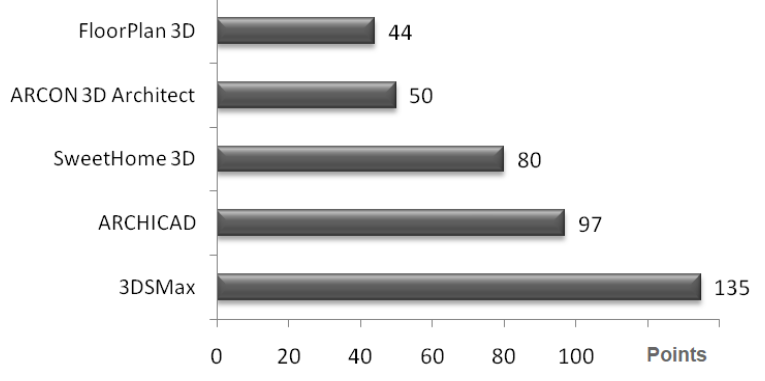

Fig. 1. Total rating evaluation of software 
After analyzing and evaluating the mentioned software according to the five parameters, the first two 3DSMax and ArchiCAD - appear the most convenient and efficient to model the Parochial Cathedral, as they are easy to use and effective in terms of time. For this reason, to build a model of the Parochial Cathedral, 3DS Max is chosen as covering all necessary tools to perform high-quality realistic rendering.

Graphic reconstruction of lost or destroyed architectural objects is a specific type of activity aimed at studying these objects in order to restore their appearance as of the time of their existence by $3 \mathrm{D}$ graphics means being guided by the preserved documents, drafts or photographs $[1 ; 3]$.

Graphic reconstruction provides for absence of precise data on an object from a single data source. It is applied to restoring a lost appearance by means of graphic and document data through collecting and combining it from various sources. Graphic reconstruction being an activity is thought of as a set of operations including data collection, object investigation and fixation prior to modelling options of a destroyed architectural monument.

The Parochial Cathedral of St. Mary of the Perpetual Assistance of the 1950s (hereafter - the Parochial Cathedral) is one of the lost historical objects of Ternopil that decorated the city centre at the corner of Ruska and Mitskevich Streets (modern Shevchenko Boulevard). Photographs and drafts are basic data sources concerning the Cathedral.

The historical and architectural key plan of Ternopil indicates that "the majestic and delicate building in the neo-Gothic style was striking in its beauty and perfection. The slim tower-spire of $62 \mathrm{~m}$ high was hovering over the city as if striving upward into the sky. It was even used as a fire tower built upon the project of the famous Lviv architect Professor Theodor Marian Tal'ovskyi" (here and after the translation is ours) [9].

The work written by L. Boitsun Ternopil in the course of years says that "in 1954, there were some explosions heard during several days when the Catholic Church was blasted. In 1959, a supermarket was opened there to celebrate the anniversary of the October Revolution. Many elements of the Church ornamentation were taken to Poland. Part of high reliefs of the sacred procession and the sculpture of Madonna were preserved in the Medium Church (the Church of the Nativity of Christ)" [10].

That is why, we consider it of great importance to restore this architectural monument to preserve Ternopil's cultural heritage. The 3D model is built on the basis of a stereogram miniature of the Parochial Cathedral photograph (Fig. 2).

Computer reconstruction implies restoration of a building in accordance with the data from the sources (descriptions, photographs, pictures) as well as some set parameters after comparing descriptions and data on construction technologies for cathedrals of that epoch.

Restoration of spacious configuration of objects is based on paraplex evaluation of images. It implies finding a relevant element in the right image for each element of the left image after processing a pair of images. The difference of horizontal coordinates of relevant pixels (paralex) reflects the distance to the image point [11].
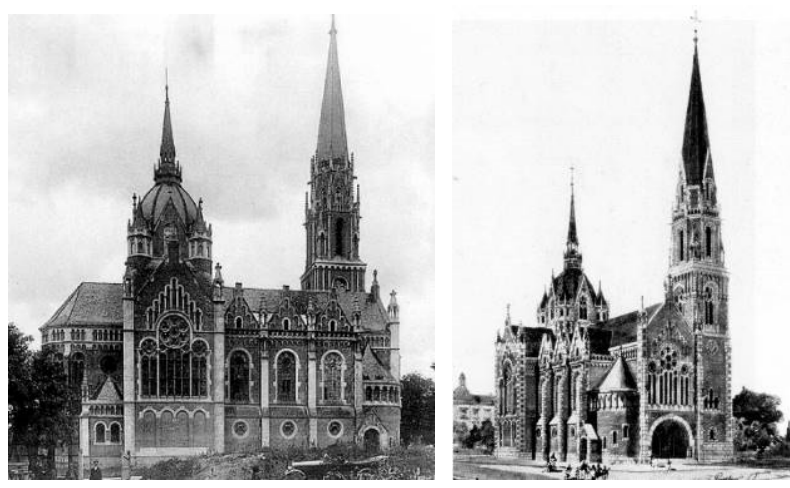

Fig. 2. The photograph of the Parochial Cathedral of St. Mary of the Perpetual Assistance (1950s)

Considering relevance of the set tasks, it is expedient to distinguish such basic stages of project implementation as analysis, design engineering (application of engineering skills), design (application of design competences), and printing (Fig. 3).

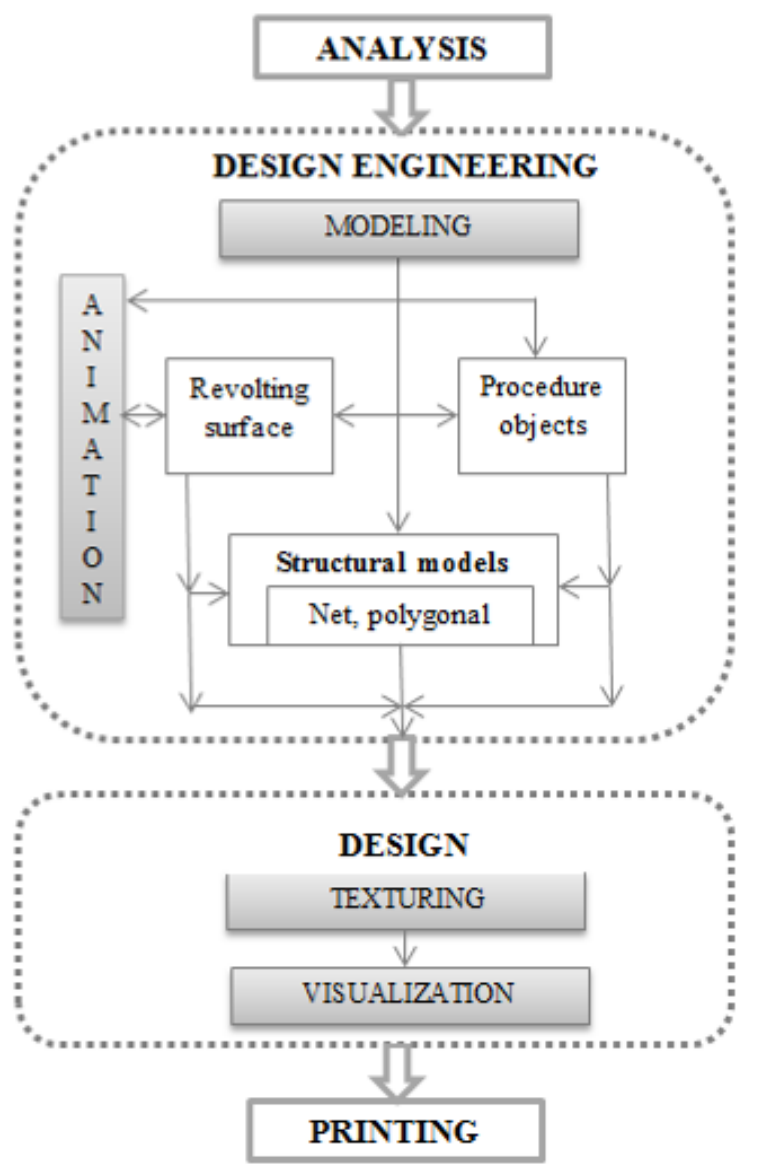

Fig. 3. Stages of project development

While analyzing, we collect necessary data on the object and required operations to build a 3D model. Design engineering involves modeling - building a 3D model and animation - providing models with 
movement or supplying auxiliary cameras and moving them along certain trajectories.

The design stage includes texturing (selection of materials and textures) and visualization (selection of light sources, change of perspectives, adjusting cameras, etc.). The finalizing stage of project development is creating a miniature of the Parochial Cathedral of St. Mary of the Perpetual Assistance applying 3D printing.

\subsection{Building a 3D model}

While building a 3D model for printing, we distinguish the following stages:

- Searching for information to create a precise model;

- Building a model in the 3DSMax environment;

- Selecting relevant sizes and building layouts of fine details;

- Preparing the model for printing.

Collection of data involves searching for cartographic materials as well as images and texts to facilitate accomplishment of the set task. Digital data are preferable followed by vector and raster images. While searching for information, we use a photograph of the Parochial Cathedral with sharp images of elements of the architectural object to create its precise model.

In applying 3D modelling methods, special attention is paid to geometrical modeling considering the type of the modeled object (engineering, design, architectural, etc.) and the technology applied [12].

Guided by detailed analysis of over 20 photographs of the Cathedral and its layout, we build a 3D model of the object. Thus, the above-described procedures result in a primary platform of the model (Fig. 4).

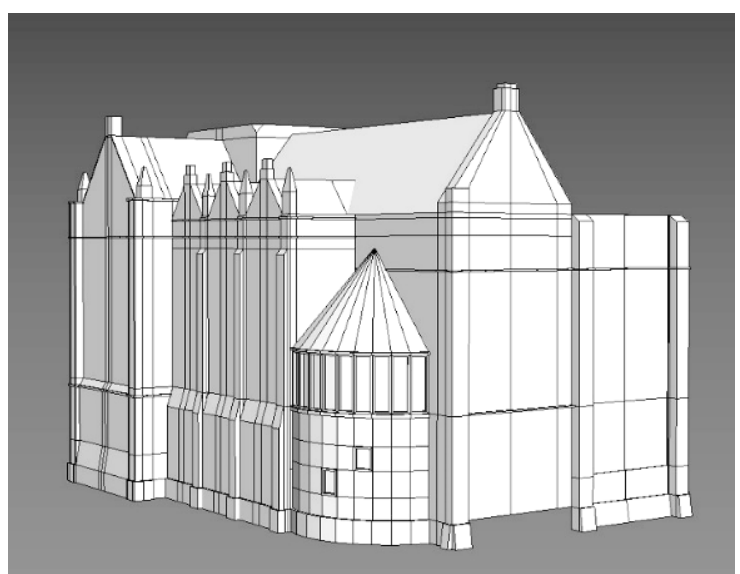

Fig. 4. The miniature of the 3D model in 3DS Max

The next actions are aimed at editing forms of the basis according to the photographs available. After completing detailed analysis of sizes and architectural features, we make amendments by means of relevant 3DS Max tools [13]. After that, the building acquires a more realistic appearance. The complex character of building the model involves numerous fine details, their asymmetry and location in different planes.

Next, we perform detailed processing of walls and domes. To reduce labour-consuming procedures of model building, repeated details like windows can be copied and dragged to the required location. If you need to resize the element, its plane or angle, then it is possible to do it using the functions of the software environment (Fig. 5).
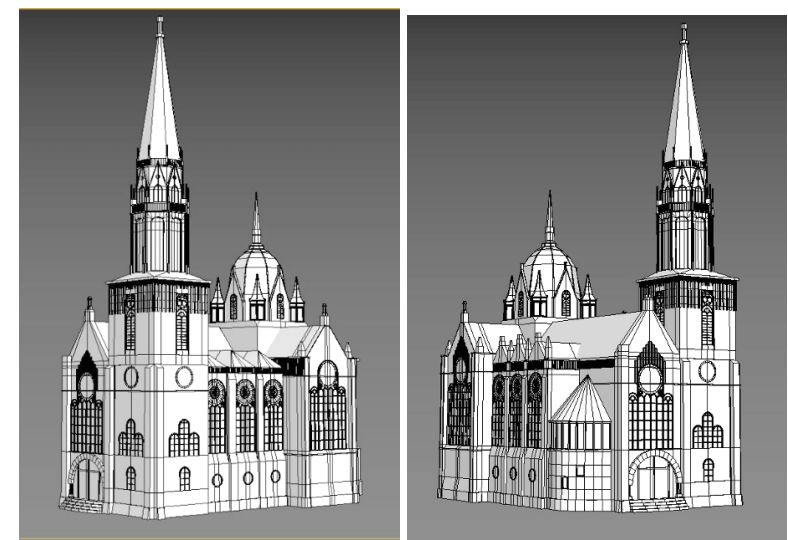

Fig. 5. The 3D model of the Parochial Cathedral of St. Mary of the Perpetual Assistance

For the sake of convenience, we apply appropriate functions to revolving and moving the model. Thus, after completing a series of actions and operations, we obtain a three-dimensional model of the Parochial Cathedral. To make the image of the model more realistic, we perform its rendering (Fig. 6).
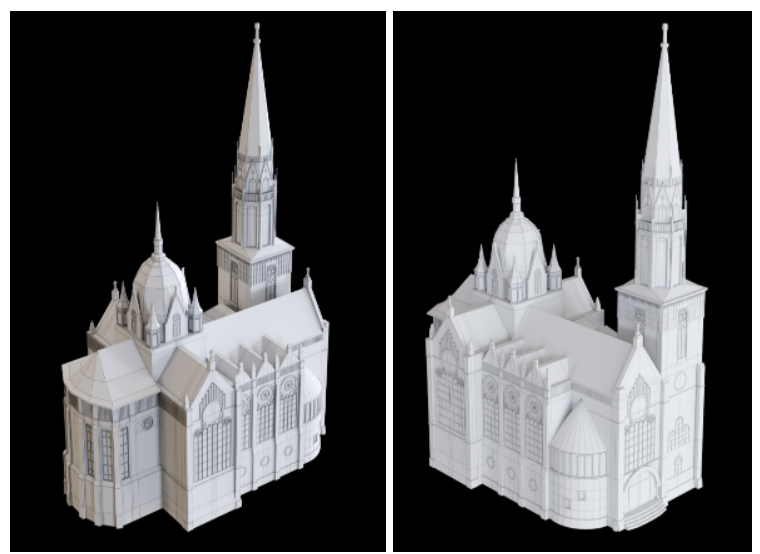

Fig. 6. The render image of the $3 \mathrm{D}$ model

Before making a printed miniature of the 3D model, we should analyze and adjust it properly. As the target result of modeling is a printed miniature, the built model should be exported into the STL-format. It should be noted that due to the intensive development of 3D printing, most specialized programs support this feature. This type supports three-dimensional objects by preserving them as a bulk of triangular data describing a surface.

\subsection{Preparing the model for printing}

The first stage of preparing the model for printing provides for analysis of 3D model geometry, which involves its testing for available open spaces in the polygonal net, some displacements of polygons and defects in geometry.

The next stage includes analysis of all parameters, sizes and their test for conformity with printing materials. As the built $3 \mathrm{D}$ model has sizes of a real-life 
building, it requires scaling to create its printable miniature (Fig. 7).

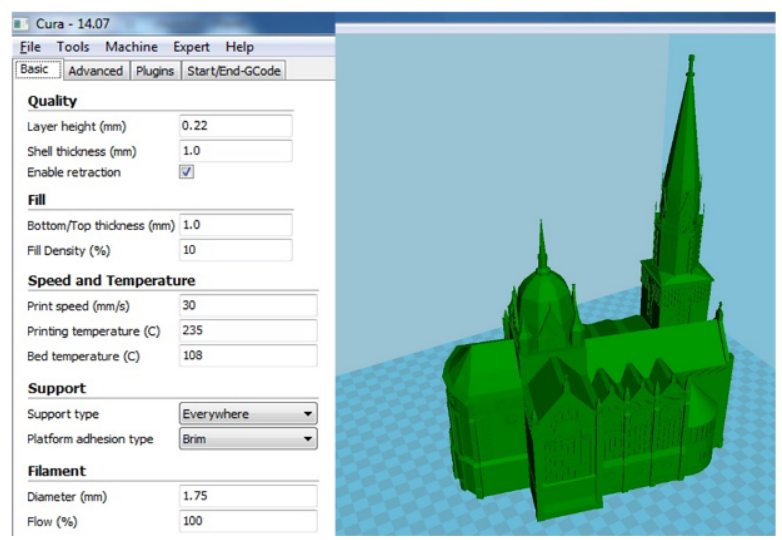

Fig. 7. Adjusting the model sizes to printing

Nowadays, there is a great variety of software for 3D printing, among which one should mention Cura, CraftWare, Slic3r, 3DTin and Repetier-Host. These software products are quite widespread due to their advanced features and relative complexity.

Yet, being guided by convenience and a relatively user-friendly interface, we apply Cura in which except for standard editing tools, printing quality adjustment and material parameters, there are functions of calculating weight of the end item, its print time, etc [14].

Basic settings of technological parameters include printing quality, filling, printing speed and temperature, parameters of printing support and plastic threads. While setting the parameters of printing quality, the most essential one is the layer height $(\mathrm{mm})$ determined by the nozzle diameter and it should not exceed its half.

Shell thickness (mm) determines thickness of printing walls of thin-wall objects or objects with the reduced in-fill ratio. Shell thickness is determined by corresponding geometrical parameters of an object. For small models, the thickness of $10 \mathrm{~mm}-30 \mathrm{~mm}$ is optimal.

Economic factors of plastic consumption are determined by fill density (\%). In most cases, the in-fill ratio makes $10 \%$, yet, for inflexible models and considering structural features of a model, the in-fill ratio can reach $100 \%$. However, printing time increases greatly.

Settings of print speed and temperatures enhance qualitative and technological parameters of printing. The most significant parameter is print speed that determines nozzle movements. As our model has many fine details, the set speed is $30 \mathrm{~mm} / \mathrm{sec}$. to make printing accurate. It is caused by the fact that high print speed affects its quality because of vibration efforts on the supporting frame of a printer and accelerated wear of drive elements.

The technology also provides for printing auxiliary model elements (not specified in geometry) considering lack of possibility to form plastic mass in the air. This support is possible for both individual model elements (support type) and its platform (platform adhesion type). In this case, we select the function Brim to provide high- quality print of model elements, which are hanging (the roof, domes). The programme creates additional supports for these elements.

After setting the required parameters to make a miniature, the file is sent to the printer with automatically formed G-code and approximate print time and the amount of the required material are determined.

Fig. 8 presents a printed model of the Parochial Cathedral based on the suggested 3D modelling technology, the advantages of which are availability and low costs of produced models.

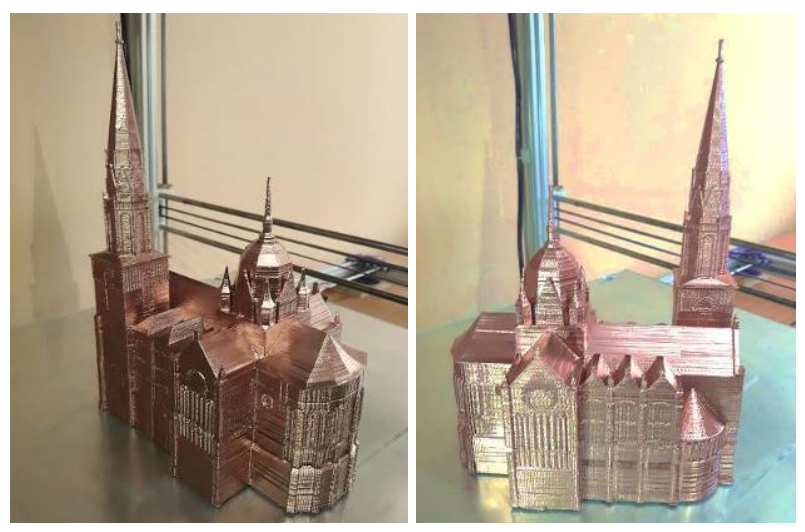

Fig. 8. The printed miniature of the Parochial Cathedral of St. Mary of the Perpetual Assistance

The methodology for creating the 3D model and printing the layout of the Parish Cathedral has been carried out by specialists of the Innovative Center for 3D-Technologies of Design and Production, which operates on the basis of the Chair of Computer Technologies of the Ternopil Volodymyr Hnatyuk National Pedagogical University.

Some specific features of the developed model indicate possible further application of the methods to reconstruction activity in order to preserve the city and the state cultural heritage.

\section{Conclusions and prospects for further research}

Graphic reconstruction of historical architectural objects is possible due to new technologies of $3 \mathrm{D}$ graphics, modeling and design in specialized computer environments. The developed methods of graphic reconstruction are exemplified by the model of the Parochial Cathedral of St. Mary of the Perpetual Assistance of the 1950s.

Stages of building 3D models of architectural monuments are based on general methods considering individual features as following from set tasks, selected software and required granularity and realism.

Stages of design implementation of the miniature of the Parochial Cathedral include the analytical stage (collection of input data; calculation of sizes and parameters of the object) and the modeling one (building a draft of an object form; accumulation, carving, stamping, etc.).

Computer reconstruction provides for restoration of a building according to the data from archive sources and parameters determined after comparing descriptions and 
data on construction of cathedrals of that epoch. Reconstruction of spacious configuration of objects is based on parallax evaluation of stereogram images of the destroyed Cathedral.

3DS Max is selected to build a 3D model of the object to enhance high accuracy, speed and granularity of fixing complex sets providing efficient tools of working with bulk data that incorporate new achievements of informational technologies.

Detailed analysis of images and determined sizes provides the basis for the 3DS Max model, which is then edited by relevant tools to make it more realistic. The complex character of building the model implies its numerous fine details, their asymmetry and location in different planes.

Creating a printed model of a 3D model requires its analysis and adaptation to $3 \mathrm{D}$ printing based on testing the model for the presence of open spaces in the polygonal mesh, defects in the geometry and checking for compliance with the print materials. To build a printed model of the Cathedral, guided by criteria of convenience and the user-friendly interface, the Cura software environment is applied.

Presented methods of building and printing threedimensional models can be successfully applied not only to graphic reconstruction of historical architectural objects, but also to teaching and learning.

Prospects for further research include restoration of the Cathedral interior that would enable creation of an object of the virtual historical museum of the architectural monument. Yet, this problem requires auxiliary data on the Parochial Cathedral of St. Mary of the Perpetual Assistance and remains unsolved to date.

\section{References}

1. L.I. Borodkin, Komp'yuternoye 3d-modelirovaniye $\mathrm{v}$ issledovaniyakh po istoricheskoy urbanistike: novyye istochnikovedcheskiye podkhody (Computer 3d-modeling in studies on historical urban studies: new source-based approaches). 21(1), 57-62 (Kostroma, 2015)

2. M.V. Rumyantsev, A.A. Smolin, R.A. Baryshev, I.N. Rudov, N.O. Pikov, Virtual'naya rekonstruktsiya ob"yektov istoriko-kul'turnogo naslediya (Virtual reconstruction of objects of historical and cultural heritage). Prikladnaya informatika 6(36), 62-77 (2011)

3. V.M. Rozhko, Metodyka hrafichnoi rekonstruktsii derevianoi naskelnoi arkhitektury (na prykladi pamiatok IX-XVI stolit Zakhidnoho rehionu Ukrainy) (The technique of graphic reconstruction of wooden rock architecture (as an example of the monuments of IX-XVI centuries of the Western region of Ukraine). (Lviv Polytechnic National University, Lviv, 2013)

4. V.V. Yavorska, I.V. Hevko, V.A. Sych, O.I. Potapchuk, K.V. Kolomiyets, Features of application of information technologies in modern tourism. J. Geol. Geog. and Geoecol. 28(3), 591599 (2019). doi:10.15421/111956
5. K. Osadcha, H. Chemerys, Dobir zasobiv tryvymirnoho modelyuvannya dlya formuvannya hrafichnoyi kompetentnosti maybutnikh bakalavriv komp'yuternykh nauk (Selection of 3D modeling tools for forming the graphic competency of future bachelors of computer science) Information Technologies and Learning Tools 62(6), 70-85 (2017)

6. V. Danylenko, Dyzain Ukrainy $u$ svitovomu konteksti khudozhno-proektnoi kultury (Ukraine Design in the world context of art and design culture). (Kharkiv, KhDADM, 2005)

7. Yu.A. Krejdun, Kontseptsiya sozdaniya galerei virtual'nykh 3D-obrazov utrachennykh pamyatnikov istorii $\mathrm{i}$ arkhitektury (The concept of creating a gallery of virtual 3D images of lost monuments of history and architecture). Vestnik Altayskogo gosudarstvennogo pedagogicheskogo universiteta 18, 71-76 (2014)

8. Ye.V. Vavilov, Seriya standartiv SQuaRE yak osnova zabezpechennya vymoh do yakosti ta otsinky prohramnykh zasobiv (SQuaRE Standards Series as a Basis for Quality Assurance and Software Evaluation). Zbirnyk naukovykh prats Odeskoyi derzhavnoyi akademiyi tekhnichnoho rehulyuvannya ta yakosti 1, 129-139 (2015)

9. Istoryko-arkhitekturnyi opornyi plan m. Ternopolia (Historic-architectural Ternopil city reference plan). (Ukrzakhidproektrestavratsiia, Lviv, 2012)

10. L.S. Boitsun, Ternopil u plyni lit. Istorykokraieznavchi zamalovky (Ternopil over the years. Historical sketches). (Jura, Ternopil, 2003)

11. D. Riabokon, Stvorennia tryvymirnykh modelei obiektiv za stereoparamy zobrazhen dlia virtualnykh muzeiv (Creating 3D object models based on stereo image imagery for virtual museums). EVA, 61-68 (2002)

12. V.A. Lytvyn, Metodyka formuvannya informatsiynoyi kultury maybutnikh arkhitektoriv (Methods of formation of information culture of future architects). Molodyy vchenyy 2(4), 159 (2015)

13. B.L. Smith, Foundation 3ds Max 8 Architectural Visualization (Apress, New York, 2006). doi:10.1007/978-1-4302-0158-8

14. V.Yu. Mitin, Obzor oborudovaniya, programmnogo obespecheniya, vozmozhnostey i etapov trekhmernoy pechati (Overview of hardware, software, features and stages of three-dimensional printing). Vestnik Permskogo Universiteta 41(2), 67-74 (2018) 